\title{
VIEWPOINT
}

\section{Two case reports of pituitary adenoma associated with Toxoplasma gondii infection}

\section{Zhang, Q Li, P Hu, H Cheng, G Huang}

J Clin Pathol 2002;55:965-966

The involvement of the pituitary in cases of toxoplasmosis has been described in the literature only rarely. This is the first report to describe pituitary adenoma in association with Toxoplasma gondii infection. The two patients were 43 and 19 year old women. Radiological examination revealed tumours in the sellar region. Microscopically, the tumours consisted of small homogeneous polygonal or round cells.

Toxoplasma cysts were found among the tumour cells, a finding confirmed by Toxoplasma gondii specific antibody immunohistochemistry. The association between pituitary adenoma and toxoplasma raises the possibility that $T$ gondii might be involved in the development of certain cases of pituitary adenoma.

See end of article for authors' affiliations

.......................

Dr X Zhang, Department of Pathology, Xijing Hospital, The Fourth Military Medical University, Xi'An, Shaanxi Province, P R China, 710032;

zhangxh@fmmu.edu.cn

Accepted for publication 17 July 2002
W e report two interesting cases of prolactin producing pituitary adenoma associated with Toxoplasma gondii infection, a finding that has not been reported previously.

Case 1 was a 43 year old woman who suffered from intermittent headaches for two years, suppressed menstruation for five and a half years, and weakened eyesight for two months. A computed tomography scan showed a tumour in the pituitary fossae, which was $2.0 \times 3.0 \mathrm{~cm}$ in size. The remaining areas of the brain were normal. There were no available hormone test results. At surgery, it was found that the tumour was well encapsulated.

Case 2 was a 19 year old woman, who was admitted to hospital as a result of recurring pituitary adenoma three and a half years after initial surgery. At this time she had suffered from inter- mittent headache and weakened eyesight of the left eye for six months. Menarche had not occurred. Gadolinium-DTPA (diethylenetriaminepenta-acetato) weighted magnetic resonance imaging revealed a recurring tumour of $2.08 \times 1.62 \times 2.80 \mathrm{~cm}$. No other abnormality of the brain was found. Serum pituitary hormone test results were: follicle stimulating hormone, $<1$ IU/litre; luteinising hormone, 2 IU/litre; prolactin, > $200 \mu \mathrm{g} /$ litre; oestradiol, $1.4 \mu \mathrm{g} /$ litre; progesterone, $1.0 \mu \mathrm{g} / \mathrm{litre}$; and testosterone, $290 \mu \mathrm{g} /$ litre. The second round of surgery found that the tumour was encapsulated. Microscopically, the tumours consisted of small polygonal and round cells with abundant eosinophilic granular cytoplasm. Tumour cell nuclei were small, with inconspicuous nucleoli and evenly distributed karyoplasm. Mitotic activity was absent. Immunohistochemistry showed that both of these tumours were prolactin producing adenomas.

Interestingly, $T$ gondii cysts were found among the tumour cells, and were verified using $T$ gondii specific antibody immunohistochemistry (figs 1, 2 ). Inflammatory cell infiltration around the cysts could be found but was not obvious.

Cases of $T$ gondii infection with involvement of the pituitary gland are rare, and include the opportunistic infection of patients with AIDS and congenital toxoplasmosis. ${ }^{1}$ Thus, the association of $T$ gondii with pituitary adenoma is both new and interesting. This finding raises the possibility that toxoplasma may be involved in the development of certain cases of pituitary adenoma. The pathogenesis of pituitary adenoma is not clear and is thought to be related to multiple factors, such as hormonal imbalance, drugs, hereditary factors, irradiation, and environmental factors. ${ }^{2}$

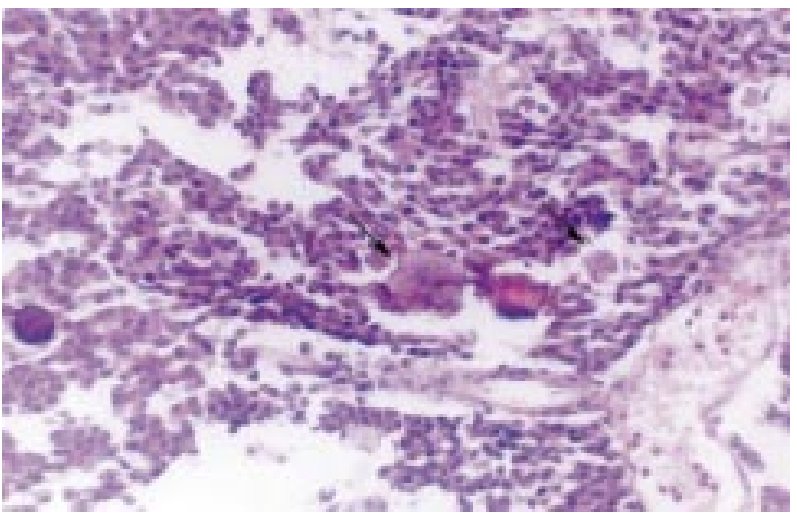

Figure 1 Toxoplasma gondii cysts (arrows) in the tumour tissue consisted of homogeneous cells (haematoxylin and eosin staining). 


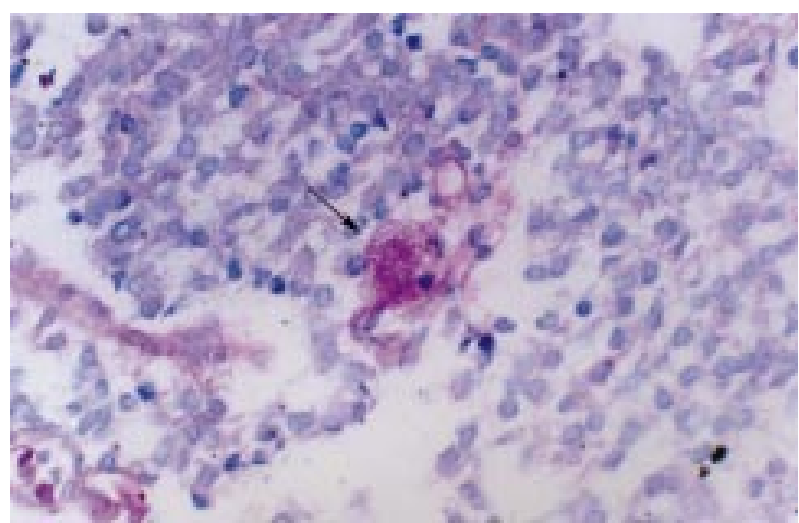

Figure 2 Periodic acid Schiff staining of Toxoplasma gondii cysts in the fumour tissue (arrow) again showing that the cells were homogeneous.

Previous experiments in which oestrogen administration to rats stimulated hyperplasia of prolactin cells and the subsequent formation of prolactin producing adenomas showed that chronic overstimulation could contribute to the neoplastic transformation. ${ }^{2}{ }^{3}$ On the other hand, exogenic prolactin can induce antiparasitic activity in microglial cells as a reaction against the $T$ gondii infection. ${ }^{4}$ Therefore, to protect against toxoplasma infection, a group of cells in the pituitary gland may proliferate to produce prolactin and thereby activate the microglial cells, and it is possible that pituitary adenoma evolves from this type of prolactin producing cell hyperplasia.

There has been some discussion in the literature about the relation between $T$ gondii infection and tumours, including primary ocular tumours, meningioma, leukaemia, and lymphoma. ${ }^{5}$ However, no further research regarding the role of toxoplasma in tumorigenesis has been done.

In summary, we report two cases of pituitary adenoma associated with $T$ gondii infection for the first time. Such an association raises the possibility that chronic overstimulation as a result of toxoplasma infection may play a role in the development of pituitary adenoma.

\section{Authors' affiliations}

X Zhang, Q Li, P Hu, H Cheng, G Huang, Department of Pathology, Xijing Hospital, The Fourth Military Medical University, Xi'An, Shaanxi Province, P R China, 710032

\section{REFERENCES}

1 Milligan SA, Katz MS, Craven PC, et al. Toxoplasmosis presenting as panhypopituitarism in a patient with the acquired immune deficiency syndrome. Am J Med 1984;77:760-64.

2 Kovacs K, Horvath E. Pathogenesis. In: Tumors of the pituitary gland. Washington DC: Armed Forces Institute of Pathology, 1983:225-32.

3 Furth J, Ueda G, Clifton KH. The pathophysiology of pituitaries and their tumors: methodological advances. In: Busch $\mathrm{H}$, ed. Methods in cancer research, Vol. X. New York: Academic Press, 1973:201-77.

4 Benedetto N, Folgore A, Romano Carratelli C, et al. Effects of cytokines and prolactin on the replication of Toxoplasma gondii in murine microglia. Eur Cytokine Netw $2001 ; 12: 348-58$.

5 Popa G, Gavrilita L, Ambarus V, et al. Relationships of toxoplasmosis with malignant neoplasias. Rev Med Chir Soc Med Nat lasi 1986;90:425-27.

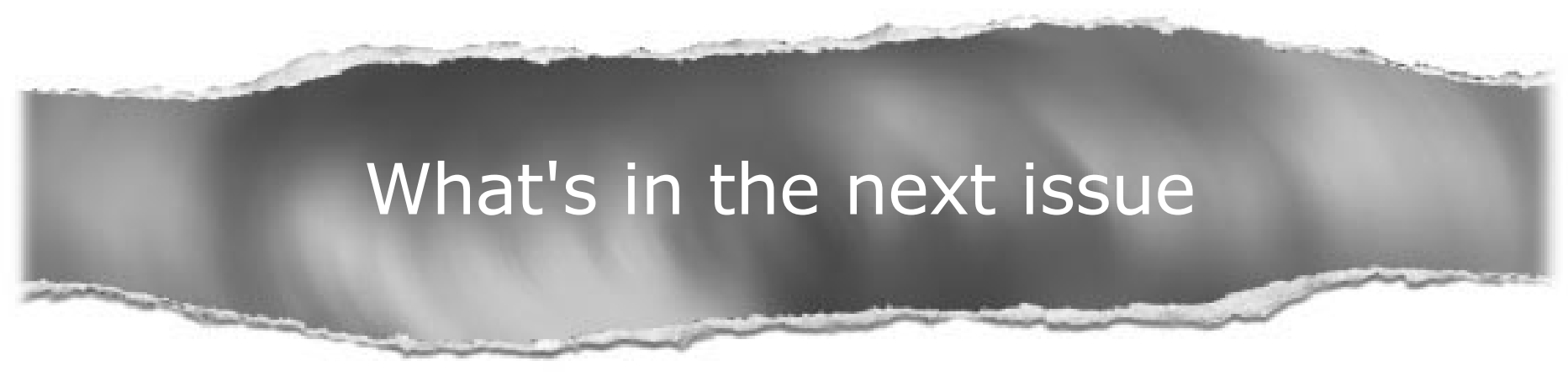

Future content

See which articles have just been accepted for publication and preview the table of contents for the next issue a month before it is published

www.jclinpath.com 